\title{
Erratum to: What are adolescents' experiences of body dissatisfaction and dieting, and what do they recommend for prevention? A qualitative study
}

Helen Sharpe · Katharine Damazer • Janet Treasure · Ulrike Schmidt

Published online: 29 March 2014

(c) Springer International Publishing Switzerland 2014

Erratum to: Eat Weight Disord (2013) 18:133-141

DOI 10.1007/s40519-013-0023-1

By an author's mistake, the article copyright was transferred to Springer before publication.

The correct article copyright line should be

(c) Crown Copyright 2013

The online version of the original article can be found under doi:10.1007/s40519-013-0023-1.

H. Sharpe $(\bowtie) \cdot$ K. Damazer · J. Treasure $~ \cdot$ U. Schmidt King's College London, Section of Eating Disorders, Institute of Psychiatry, De Crespigny Park, London SE5 8AF, UK e-mail: helen.sharpe@kcl.ac.uk 